\title{
14 Food-related Yangsheng short videos among the retired population in Shanghai
}

\author{
Xinyuan Wang and Vivienne Lo
}

Despite an emerging and significant impact upon daily life (Lomborg 2014), health and self-care in China, the popularity of smartphone-based short videos (duan shipin 短视频) has not yet drawn enough attention from either anthropological study or the Medical Humanities. The research of this chapter is part of an ongoing long-term (Feb 2018-June 2019) ethnographic research among the retired population in Shanghai, with a specific focus on the use of short videos and their influence and potential for influence upon everyday health and self-care.

Self-care in China has a unique history which is related to the practice of yangsheng 养生, literally translated as 'nourishing life', 'nurturing life', or 'cultivating life'. Yangsheng has more than 2000 years of history that refers to a broad range of ever-changing practices that have been taught and practised in domestic, religious, and educational contexts. The purpose of the practice is to promote well-being in individuals and communities, to generate strength and resilience, as well as an acuity of the sensory or spiritual faculties among the practitioners. Many activities are attributed yangsheng qualities: martial arts, sexual regimen, singing, calligraphy, and even the keeping of song birds or other pet animals (Dear 2012). This chapter looks at how yangsheng is achieved through the use of foodways, and the survival into our times of the close relationship between food and medicine.

In order to gain long-term participant-observation (Miller and Slater 2000; Pink 2001) among the ageing population, the ethnographer, Wang, moved into an ordinary residential compound called ForeverGood ${ }^{1}$ in the city centre of Shanghai. Established in 1947, the gated ForeverGood compound consists of 23 residential buildings, housing more than 3000 residents and 941 households. The average age of the residents of ForeverGood village is around 60, with $32 \%$ over $60,6 \%$ over 80 , and two residents over 100. Besides in-depth interviews, field work has been conducted mainly along with/through various volunteer work and daily engagements in the residential compound - from helping the resident committee office (juweihui 居委会) to compiling the oral history of the community to giving free English lessons for the residents; from joining the local self-care group to making friends and keeping contact with individual neighbours offline and online (via social media). This chapter is based on ethnographical material gained among 35 retired participants through in-depth interviews and interactions on a daily basis 
over eight months from February 2018 to November 2018 (19 females, 16 males; average age 65).

After introducing the significance of short videos in the context of the transforming landscape of personal communication in the age of the smartphone, this chapter focuses on the everyday deployment of short videos (Mohammid 2017) in the discourse of health and yangsheng. Based on the observation of the general use of smartphone-based videos as well as historical inquiry into traditional beliefs in the close relationship between diet and the aims of yangsheng, the case studies lead to the discussion of the impact of the short videos upon Chinese traditional yangsheng practice.

\section{Short videos in daily communication}

One of the most common daily greetings in ForeverGood, shared with people all across China, is 'have you eaten?' (chi guo le ma? 吃过了吗?). The collective concern for regular feeding is a cultural idiosyncrasy which has been widely recorded and analysed in multiple academic researches and popular writings for how it reflects the significance of food in Chinese social life. Following closely behind this most commonplace greeting comes another opening line which triggers small talk among residents - a line which has been spotted only recently on a few occasions and seems to suggest the emerging importance of another popular daily activity - the sharing of short videos via smartphones.

'Have you checked the video I sent to you?', Ms Shi frequently opens her daily chit-chat with her neighbours when they meet at the after-dinner stroll in the neighbourhood. 'Yes, just watched, very useful! I have forwarded it to my family group. Have a look!' one neighbour, Ms Cai, replies, pulling out her smartphone. Ms Cai opens her WeChat ${ }^{2}$ and quickly swipes down the screen, clicking on the video Ms Shi means, and passes the screen to other neighbours who are loitering in the vicinity. It is a one-minute video illustrating how to massage the acupuncture point kunlun xue (昆仑穴) near the ankle to treat sciatica and arthritis. Like many peers in their 60s and 70s, both Ms Shi and Ms Cai started to use the smartphone as well as social media around two to three years ago and soon became heavy users who would spend a self-estimated minimum of three hours per day on it.

The ownership of the smartphone among residents under 65 is more than $90 \%$. Even though the majority $(90 \%)$ over 80 do not use smartphones, there are a few who have taken it up with great passion. Experience and knowledge of smartphone use, they feel, is a sign that they are forever young. Activities facilitated by short videos account for a remarkable percentage of the usage time of smartphones. The length of the video on these platforms is one of key factors which defines its accessibility and popularity (also see Mohammid 2017), the majority being very short, from ten seconds to 2 minutes. For example, the logo of the short video platform Miaopai (秒拍) (lit. 'seconds shooting') is 'shoot a blockbuster in 10 seconds'. Being very short means that the video files (rather than web links) are small enough to be easily sent as messages. ${ }^{3}$ In most cases, people received short videos from a variety of WeChat contacts. 
The year 2017 witnessed a spurt in the availability of short video apps in mainland China. By the end of 2017, there were 334.1 million active users of short video apps in a month. ${ }^{4}$ According to a recent report, ${ }^{5}$ with 45 million downloads worldwide, Douyin (抖音), a newly launched Chinese short video app dominates the iPhone download. The popularity of short videos also emerges among the retired population who are generally regarded as the less digitally savvy population. Despite the fact that less than $10 \%$ of the participants had been to the cinema in the previous six months, all the participants watched short videos on smartphones; and more than $70 \%$ of them watched short videos on a daily basis. Almost one-third of them watch short videos for more than one hour per day.

In her early 60s Ms Jiang has become a big fan of short videos. In order to take her smartphone wherever she goes, Ms Jiang sewed a pocket into her apron. From time to time when she sits down for a short break in the middle of her housework, she pulls out the smartphone and clicks all the 'new-in' videos people have shared in four different WeChat groups (two alumni groups, one previous neighbours group, one family group) and those which were sent to her directly by a few of her good friends.

Like Ms Jiang, retirees are very keen on short videos and have accepted it as a form of daily communication as well as an important information resource (Okabe 2006). Mr Zhang in his 70s is also representative of this group. He explained why short videos have won his heart:

They (videos) are much better than text, I need a magnifier to read small fonts on this small screen. But I can watch videos without any problem. Video has sound and moving pictures, very effective and engaging ... nowadays the content of short videos is just so rich ... I watch short videos everyday also to keep myself aware of the ever-changing world.

The majority of short videos Mr Zhang receives are less than one and a half minutes long, and some of them are just 15 seconds. In the previous week (16-22 April 2018) Mr Zhang had clicked through more than 100 short videos, ranging from funny cat videos to Traditional Chinese Medicine (TCM) yangsheng tips. From a cinematographic perspective, most short clips were made in a rather 'amateur' way. The majority of the video clips that circulated on smartphones were shot on ordinary smartphones without any choreographed camera direction or professional lighting. In many cases, the storytelling is as straightforward as one can imagine - either talking directly to the camera, or video/slides with background music plus voice-over. Also, in many cases, the videos are short cuts from a longer film or TV programme. The resolution of most short videos is therefore much below the quality needed for showing on the big screen. As Mr Zhang argues, the richness of short videos not only lies in their multimedia features, but also in the content. Common topics of the short videos shared among retired people include 1) funny or unusual videos of animals, people, and design; 2) entertaining performances such as singing, dancing, acrobatics, magic, etc.; 3) yangsheng tips; 4) news; and 5) lifestyle guidance and tips. 
Among retired urban populations short videos about yangsheng are one of the most watched and shared in the genre. This fact leads us to explore further the daily practice of modern yangsheng, the classic TCM concept of self-care, as it is changing in the digital age. In order to do so it is first necessary to consider the historical relationship between yangsheng and food.

\section{Yangsheng and food}

Historically, food and drug culture in China was not limited to curing illness; the potential for herbal, mineral, and animal products to fortify and stimulate the body was well-known in ancient China. Food and drugs were an integral part of a regimen aimed at longevity, immortality, and even the preservation of the body beyond death. Recipe collections testifying to the antiquity of these traditions have been recovered from the tombs of Han China (Lo 2005). The early remedies often combined foodstuffs, common herbs, and household substances, with a view to healing specific illnesses, but also simply to promote health and wellbeing. Discovering the aphrodisiac qualities of food was a key context within which nutritional knowledge flourished at that time (Lo and Re'em 2018).

Over the following millennium each individual ingredient was systematically assigned medical efficacy according to classical Chinese scientific categories. The most fundamental of these categories were yin 阴 and yang 阳 which ordered the world in terms of complementary opposition. Something was not to be spoken of as yin or yang either absolutely or in isolation. In foodstuffs, the oppositions of heating and cooling or upward and downward (emetics and purgatives) are most often encountered.

Each substance not only had yin or yang qualities, but it also had a wei 味. Historians of Chinese medicine often translate wei as 'sapors' rather than 'flavor', the common translation, to distinguish medical rather than culinary virtues. $W u$ wei 五味, the five flavours, often cited in early Chinese literature, refer generally to the range of sensual pleasures that one might dream of consuming, but in a medical context, they were also specific flavours that could stimulate certain movements of qi 气, the essential 'stuff of life' that animated and invigorated the body, making a person astute, healthy, and effective (Unschuld 1986: 205-28).

By late medieval times there was an effective synthesis of all the observations and theories about the effects of food. Foods, like drugs, were classified according to their thermostatic qualities (hot, warm, neutral, cool, and cold), by flavor (pungent, sweet, salty, sour, and bitter), by the directions in which they induced movements within the body, by the organ system that they supported, as well as by the symptoms of illness that they could influence.

Sweet, for example, was thought slightly yang in nature and promoted an upward and outward movement. It entered the stomach and spleen channels. Mildly sweet foods, such as grains, nuts, fruits, and many vegetables, should form the main bulk of any diet. Stronger sweet flavours have a very warming and nourishing effect but should be avoided by people with signs of damp. 
Saltiness moistened the body, while sour gathered and contracted, cleansing the body and moving the blood. Saltiness entered the kidneys and sour, the liver. Bitter was the most yin of flavours. It caused contraction and made qi descend and move inward reducing fever and calming agitation. It was also drying and therefore good for dampness. Bitter entered the heart clearing heat and calming the spirit (Lo 2005).

In general, medical priorities demanded restraint with a distinct moral overtone aimed at the leisure classes: too much strong meat, spice, oil, and fat would create excess heat, while raw vegetables and cold food and water were indigestible and harmed the stomach. Balance, harmony, and the careful intervention of the chef in cooking were keys to a healthy diet.

If we focus on the physiological effects of the foodstuffs and the mix of food and drugs in the pharmacological treatises, there is little to distinguish food from medicine. In practice, medical advice from the medieval period advised beginning with the gentler dietary therapy: Sun Simiao 孙思邈 (581?-682 CE) wrote:

The nature of drugs is hard and violent, just like that of imperial soldiers. Since soldiers are so savage and impetuous, how could anybody dare to deploy them recklessly? If they are deployed inappropriately, harm and destruction will result everywhere. Similarly, excessive damage is the consequence if drugs are thrown at illnesses. A good doctor first makes a diagnosis, and having found out the cause of the disease, he tries to cure it first by food. When food fails, then he prescribes medicine. ${ }^{6}$

Thus, the best doctors diagnosed and treated the body with dietary advice before illness manifested. By attributing thermostatic and other physiological effects to every foodstuff, medical authors embraced nutrition within a larger framework of knowledge, thereby providing the rationale for what became an enormous and influential tradition of food combinations and prohibitions (Despeux 2007).

From the Han dynasty onwards we know that literate families shared recipes and recipe books as evidence of their participation in culturally elite patterns of consumption. By the Ming and Qing there were also formal materia dietetica modelled on the drug remedy books. By then much of this knowledge also formed part of the common knowledge of ordinary people. No doubt there were vibrant oral traditions at lower levels of literacy and between women. In the mid-twentieth century Chinese medicine was undergoing a revolution. Post-'liberation' 1950s China saw the creation of a new discipline of Chinese Medicine, which meant that the past was being used (and in many senses re-created and re-configured) to serve the present and the future. It was to become a medicine of the people (Taylor 2005), thoroughly modern and institutionalised. Whereas the norm elsewhere in constructing 'modern' scientific medical systems was to discard the 'pre-scientific' past, the new revolutionary government intended to incorporate and scientise Chinese medicine. Given that dietary medicine shared the same epistemological basis as Chinese pharmacology the standardised tenets of the new institutional Chinese medicine applied to nutrition, but the nutritional domain was always less professional allowing lay authority to flourish. 


\section{Food-related yangsheng short videos in everyday life}

The 30-member strong 'healthcare self-management' group of ForeverGood has started to self-teach itself the TCM acupuncture system of the channels (jingluo 经络). 92-year-old Ms Cai is a member of the group. In Ms Cai's flat, plastic bags filled to the brim with traditional medicines pile up on top of the closet. Like many older people, she has a very high opinion of the efficacy of traditional therapies. When she was suffering from a tumour in her lungs, one of her friends recommended traditional medicines, and now the nodule is much reduced. 'TCM is magical!' Ms Cai claimed. Ms Cai is not alone, the majority of older participants in Shanghai view TCM as one of the most obvious ways to maintain their health.

Mr Liang, a retired engineer in his $80 \mathrm{~s}$, had a heart operation last year, and since then he had to take three different kinds of 'western' medicines every day. Yangsheng is now what concerns Mr Liang, he said:

Yangsheng is not about fixing the problem, it is very holistic, it is about keeping a well-balanced lifestyle. If you really follow the principles of yangsheng, then you won't even be vulnerable to getting ill and have to take western medicine. ... Now I have to respond with western medicines to save my life, that is the cost I have paid for living unhealthily in the past decades, ignoring yangsheng.

As Mr Liang said, the concept of yangsheng is accepted and practiced as a healthy way of living. People also take western medicines when they are ill while still seeing TCM yangsheng as a long-term self-care practice engrained in everyday life. As mentioned in the last section, food has long been regarded as the most important part of yangsheng. It is very common to see the daily discussion and practice of yangsheng manifest itself in the extra attention paid to the medical function of food from a TCM perspective. Consequently, food-related yangsheng short videos, in particular, are popular among retired people.

Ms Mao, in her early 60s, prepares 'tonic' ( $b u$ 补) soup made from Chinese Angelica root (danggui 当归), ginger, and lamb for her good friend's husband who has lost his ability to take care of himself because of a stroke. Ms Mao learnt how to cook such tonic soup from her aunty, but recently she was delighted to find a short video which also teaches people how to prepare this soup (Figure 14.1). Besides watching how to cook healthy dishes, Ms Mao has also collected and stored more than 30 short videos on her smartphone about topics such as 'What kind of food should rheumatic patients take during the summer rain season (meiyu 梅雨)', 'During the hot summer, what kind of food will help rid the body of dampness (shiqi 湿气)', 'What kind of food people with liver problems should avoid', etc. Ms Mao explained:

These short videos are straightforward, usually I can learn (a recipe) immediately when I watch it once. If you forget you can always go back 


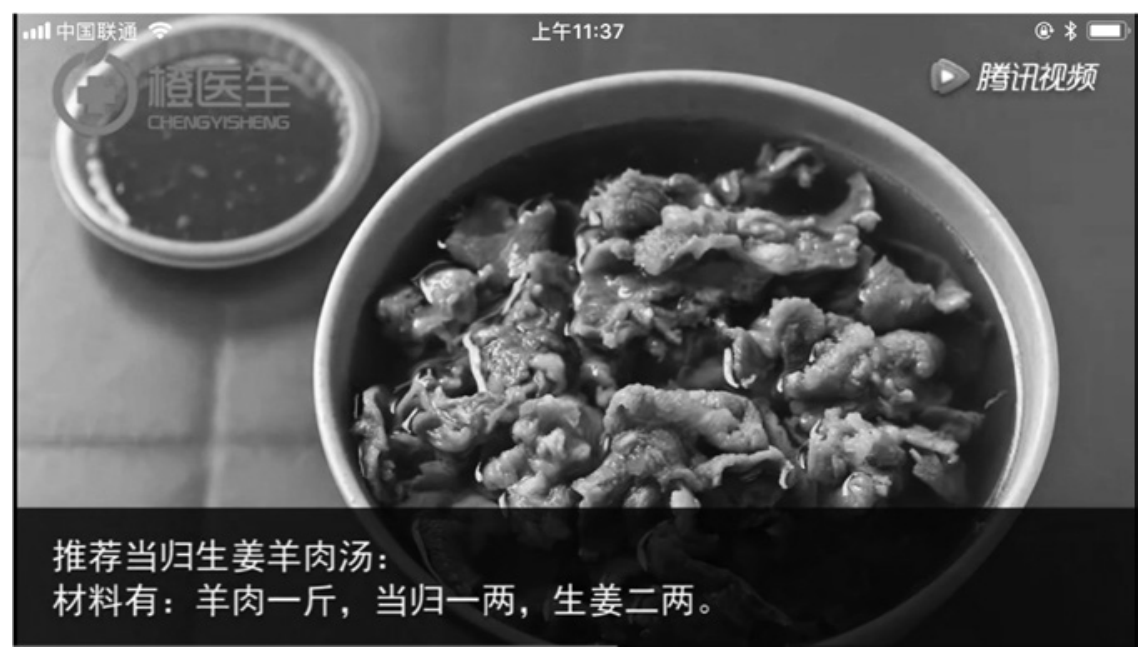

Figure 14.1 Screenshot of recipe for tonic soup

to check. It is also very convenient to share them with others who you care about, you simply click a few times. For example, I heard an old friend of mine was suffering from rheumatism, I sent him this video about the benefit of green bean soup . . . A previous middle school classmate of mine told me the other day that her daughter-in-law, 39, is pregnant again. I recalled a few days ago I watched a short video talking about food restrictions for older pregnant women, so I forwarded this video to her.

Another example comes from Ms Fan in her late 50s. Ms Fan is a retired middle school teacher, now regarded as a yangsheng expert among her friends. Knowing one of her neighbours, Ms Yu, suffers from mood swings and bad sleep, Ms Fan suggested:

I think you probably have liver Qi stagnation (ganqi yujie 肝气郁结). Try and have some siwu decoction (siwutang 四物汤). It is good for women, easy to prepare. I will send you the short video later when I am home.

'Liver Qi stagnation' is one of the most commonly experienced patterns identified in TCM, and it seems that all the participants above 50s have heard about such medical expressions, even if they have not entirely understood their meaning. As shown on the screenshots below, the two videos Ms Fan sent to Ms Yu via WeChat are both very short; the first one is about one minute, the second one two and half minutes. The first one is taken from a TV programme called The path to health (Jiankang zhilu 健康之路) on channel 10 of China Central Television (CCTV). In this TV program a TCM expert was invited to give a lecture on the benefits of the siwu 
decoction (Figure 14.2). This decoction is widely used to 1) tonify and invigorate the blood; and 2) regulate the liver, harmonise the menses, and alleviate pain. It is made from four herbs: processed Chinese foxglove root (dihuang 地黄), white peony root (shaoyao 药药), Chinese Angelica root (danggui 当归), and Szechuan lovage root (chuanxiong 川芎). The second short video illustrates how to prepare the decoction with these four medical materials (Figure 14.3).

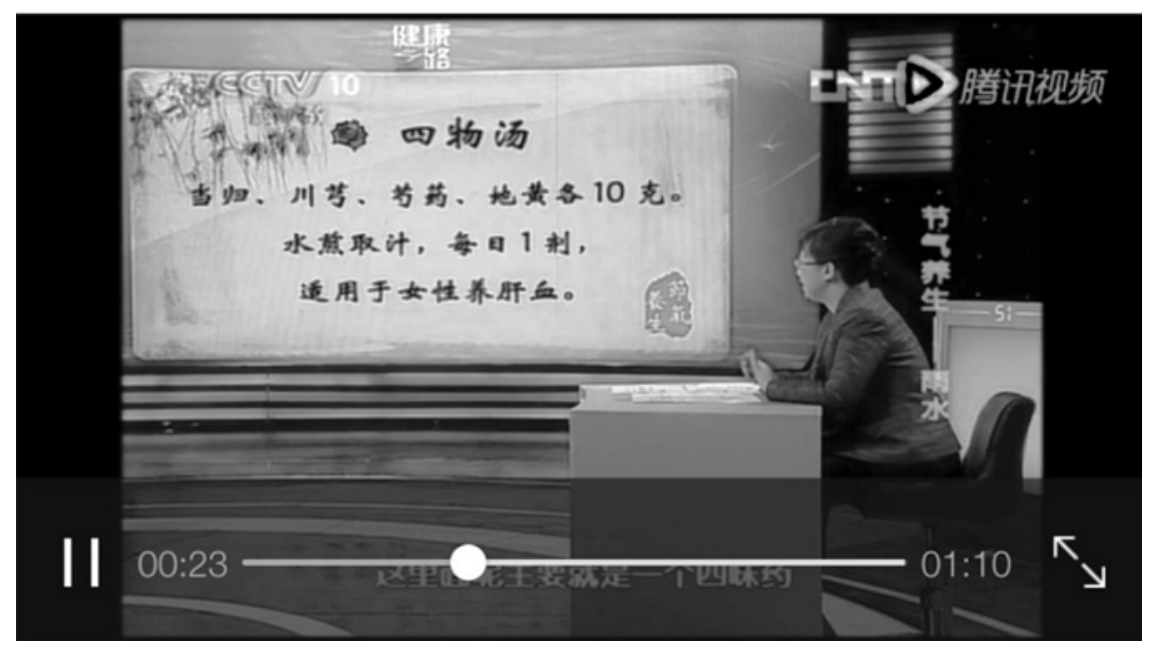

Figure 14.2 Screenshot of one-minute short video on the benefits of siwu decoction.

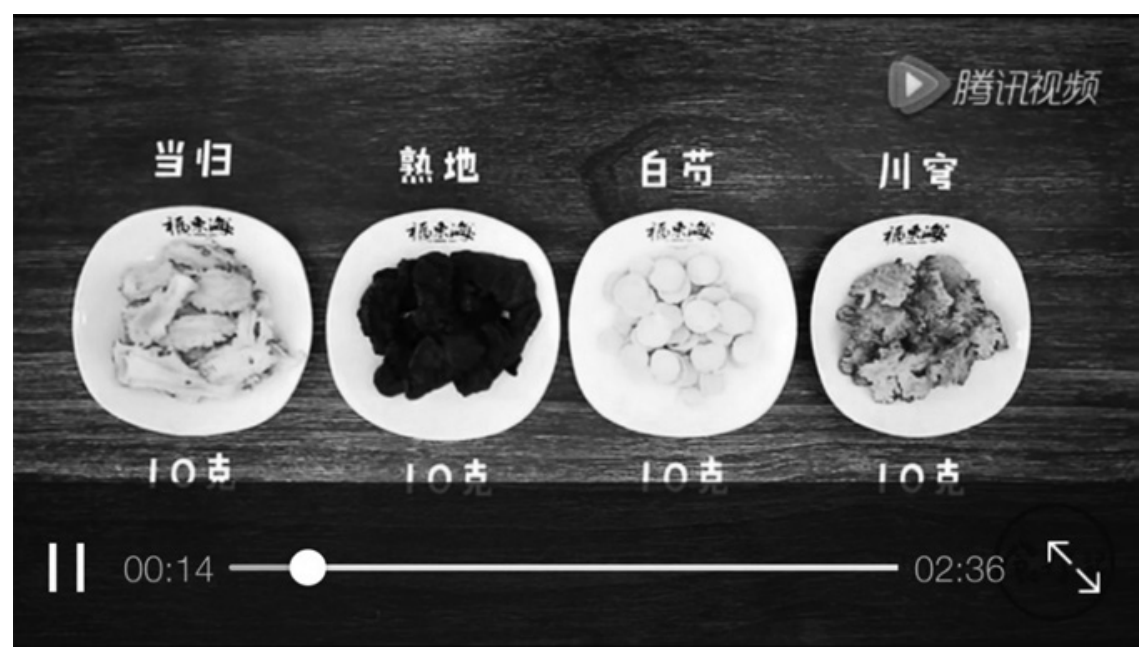

Figure 14.3 Screenshot of short video illustrating the preparation of siwu decoction 
$\mathrm{Ms} \mathrm{Yu}$ was pleased by the two short videos. Asked why she believes in the nutritional advice of these short videos, she replied,

They are not random videos . . . they were sent by my old sister (lao jiemei 老姐妹), I know she has good knowledge of yangsheng. She is very kind and caring ... so you can trust it. We were not well educated when we were young because we didn't have opportunities, ${ }^{7}$ but we can still learn things from the internet and from each other.

To share a concern for another's health is perceived as an endorsement of the relationship (Chambers 2013). Also, to inquire about the health of others, especially the older people, is regarded as an appropriate way of showing respect as well as caring. In both cases mentioned here, the yangsheng short videos are not only regarded as convenient health information resources, but also the ideal media to express caring. By 'simply clicking a few times', social relationships are maintained at a relatively low cost. The practice of video watching and sharing has actually embedded in a wider social process than what we find online. People accessed online videos to get information and to build their knowledge, but the learning and dissemination of information is largely enacted in offline relationships that express caring and build solidarity among family members and friends.

\section{Yangsheng short videos and food restrictions}

Among the Yangsheng videos to do with food, there is one specific genre about 'food restrictions' (shiwu xiangke 食物相克) which has attracted remarkable attention among the ageing population. 'Taking the right food at the right time is very important, the failure to recognise food restrictions can cause a lot of problems'. Mr Zhu, a man in his late $60 \mathrm{~s}$, refers to an ancient tradition of dietary prohibitions summed up by the seventh-century physician, Sun Simiao. Sun emphasised the importance of dietary prohibitions in his chapter on dietetics:

If the Qi of different foods are incompatible, the essence will be damaged. The body achieves completion from the flavors that nourish it. If the different flavours of foods are not harmonized, the body becomes impure. This is why the sage starts off by obeying the alimentary prohibitions in order to preserve his nature; if that proves ineffective, he has recourse to remedies for sustaining life. ${ }^{8}$

The emphasis on correct patterns of eating to protect the body's essences would mean that medical drugs were only appropriate when food combinations and prohibitions failed. There are multiple historical layers of food prohibition that underpin the restrictions recommended by residents of ForeverGood.

Traditionally food prohibitions embrace empirical knowledge about food hygiene and seasonal eating, Buddhist precepts that strive for purification through dietary means, the traditional nutritional science of the correct flavour/sapor 
combinations and their influence on inner organ function, not to speak of regional culinary wisdom about what combinations are unpalatable.

The way in which Mr Zhu and his wife regulate their daily food intake according to the principles of 'food restrictions' (shiwu xiangke) provides an illuminating example.

Mr Zhu has had high blood pressure for more than 8 years. His wife Ms Zhu takes close care of his daily food intake. 'Vegetable and fruits are the best for our health, meat does nothing good'. Ms Zhu would buy onions at least twice every week as onion is believed to be effective in lowering blood pressure as well as an anti-cancer agent. The couple also take honey with hot water in the morning, as it is said that honey every morning can help prevent constipation and can also battle chronic coughing. However, the couple believe that the two very healthy foods, onion and honey, are not supposed to be taken together. Ms Zhu said:

Onion is good for everything, but you can't take onion and honey together as such a combination is not good for the eyes!

In order to drive home her point, Ms Zhu played a short video about food restrictions related to onions (Figure 14.4) which a good friend of hers had sent to her on WeChat a few weeks previously (Figure 14.5).

Besides making an effort to avoid harmful combinations of foods, the couple pay extra attention to what food they take during the period when they are taking TCM in order to maximise the effect of the medicines. They usually take some TCM medicine in the beginning of summer and winter to help the body to adjust to the changes of season smoothly - 'to tone your body' (tiaoli shenti 调理身体)

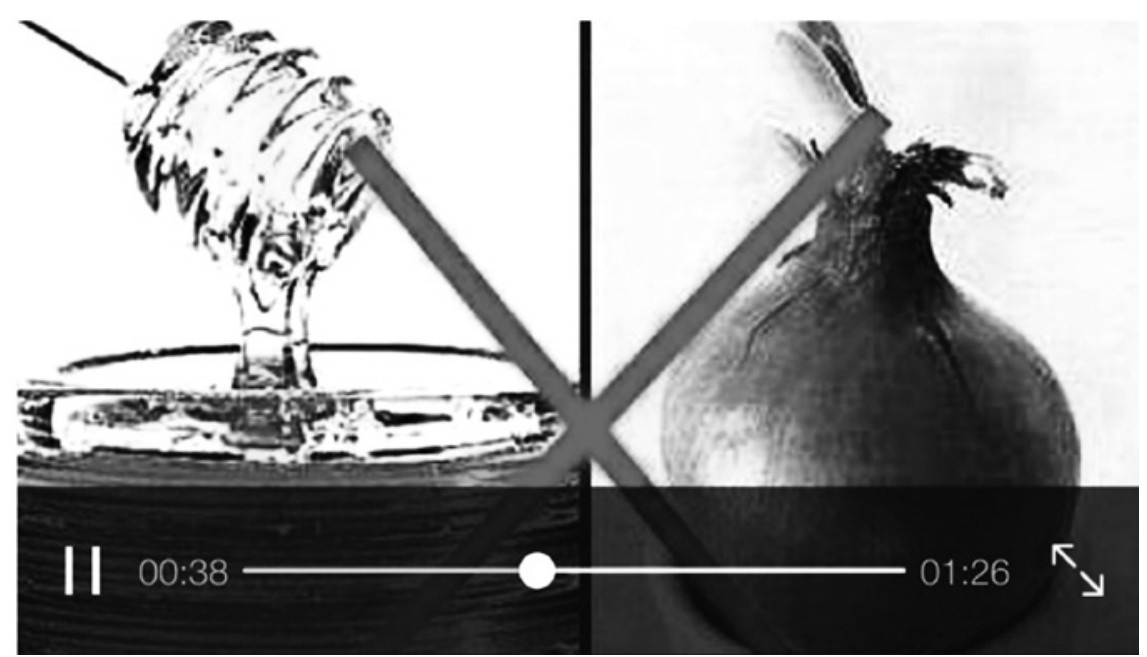

Figure 14.4 Screenshot of a one-and-half-minute long video clip about the prohibition against eating onion and honey 


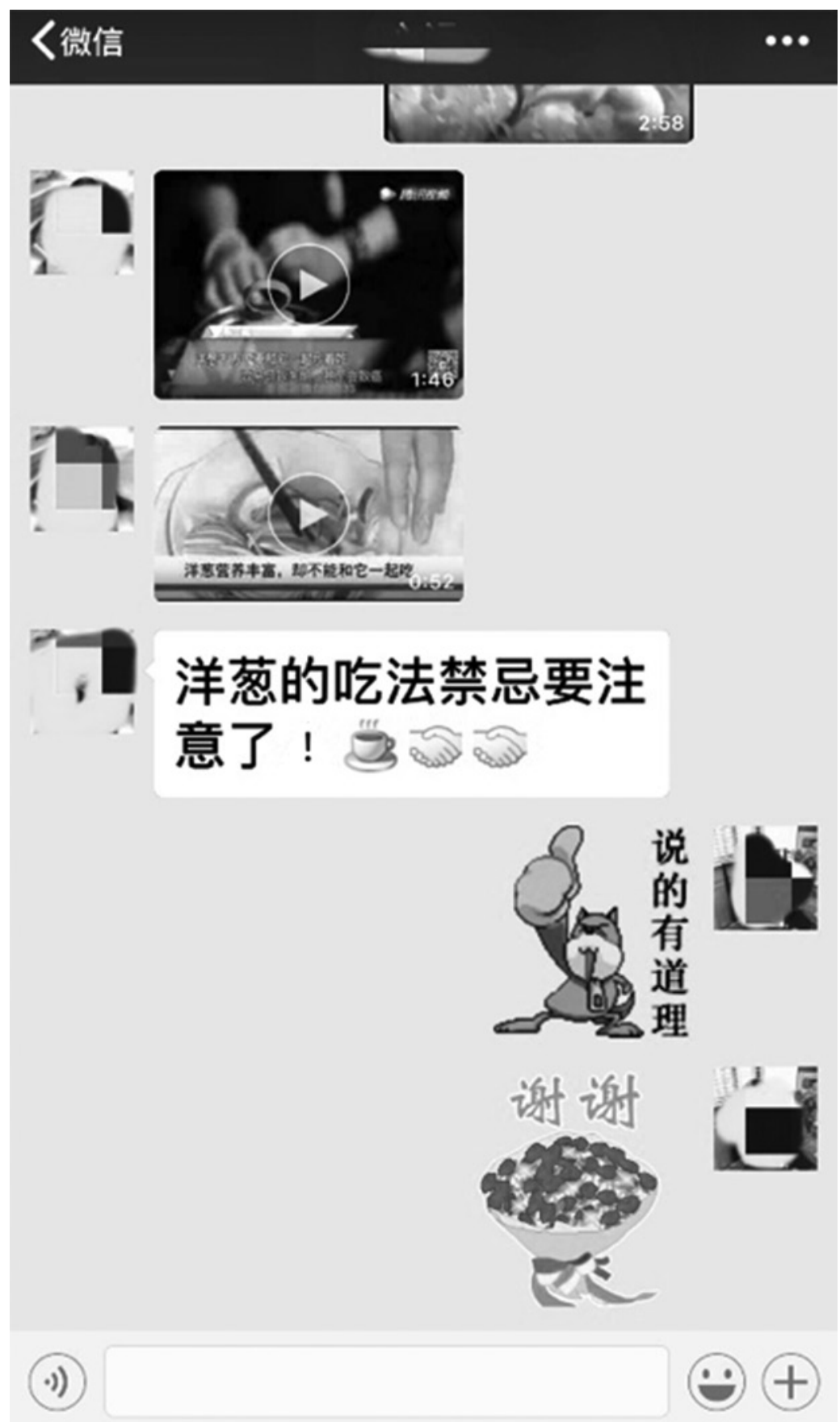

Figure 14.5 Screenshot of the WeChat conversation log between Ms Zhu and her friend who sent her the short videos of food prohibitions. The comment reads 'pay attention to the prohibitions of eating onion!', and Ms Zhu replies by two emoji: one says 'it makes a lot sense' with a cartoon character giving a thumbs-up gesture, the other says 'thank you' with a bunch of flowers. 
as they said. Recently, they have been taking a TCM soup with ingredients like ginseng (rensen 人参), and atractylodes (cangshu 苍术) to strengthen $Q i$ in summer, and they avoid taking turnips (luobo 萝卜). Mr Zhu explained:

Ginseng is to strengthen the Qi while turnip's properties promote digestion and eliminate excessive Qi. So basically, these two are doing contradictory things to Qi. Therefore, we need to avoid turnips if we are taking ginseng.

Ms Zhu used to keep a long list of detrimental food combinations in a cutting from a local newspaper. She kept it sandwiched underneath the transparent mat on her dining table, 'I put that newspaper cutting on food restrictions just at the right corner of the table where I sit, so that from time to time when I was having meals I could look down and learn it by heart'. That yellowed paper cutting disappeared when they changed the dining table. However, Ms Zhu no longer needs that piece of paper as she can always check WeChat.

It is common to see retirees keeping the knowledge of 'food restrictions' in the form of newspaper clippings or handwritten notes. Ms Wang (71) still keeps a handwritten list of food restrictions underneath the transparent mat of her dining table (Figure 14.6).

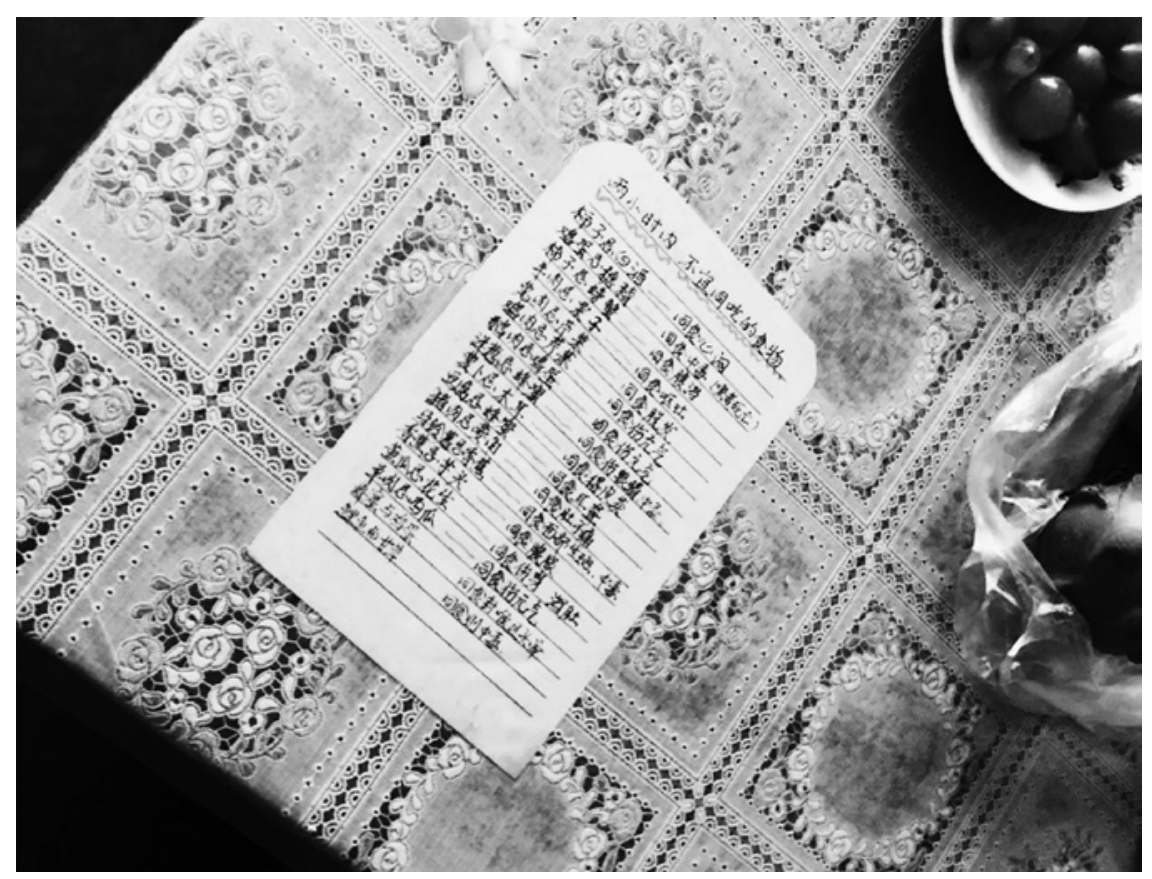

Figure 14.6 Handwritten list of food prohibitions by Ms Wang 
CCTV, China's state television station, has taken a strong stance against the TCM concept of 'food restrictions' labelling such belief in the poisonous interactions of certain food combinations as spreading 'false rumors'. In 2018, the 'March 15th National Day for protecting consumer's rights' Gala, covered by CCTV-2 channel, included a programme segment in which food prohibitions such as shrimps and red dates, crab with tomatoes, durian fruit and milk, were debunked by laboratory testing.

Short videos showing CCTV debunking food restrictions are also available online, however they do not find an audience among retired people. When the ethnographer showed the retired engineer Mr Liang a video of CCTV debunking the food restrictions, Mr Liang commented:

Yangsheng is Chinese wisdom of hundreds of years; it is beyond anything western science can test, don't you know? These tests are not long-term, I think it is short-sighted to value a thing only with reference to lab results. Many things cannot be lab tested.

Compared to him, Ms Yu seemed more convinced by the video, saying:

Ah, good! It's good to know the consequences of eating the 'fatal combination' is not that deadly. But to be honest, I would never eat these two together anyway, with or without the restriction.

Meanwhile, the couple $\mathrm{Mr}$ and $\mathrm{Ms} \mathrm{Zhu}$, who follow food restrictions strictly in their daily life, expressed some reservations. Mr Zhu opined:

When you get older, you will know that not everything can be explained properly and neatly. Our body system is very complicated. These food restrictions are the experience of many generations. For the sake of my health, I would rather believe than ignore them and feel regret later on.

This feedback is representative of general attitudes among the retired population towards the wider debate in China about the efficacy of TCM vis-à-vis a 'western' medicine based on lab science. The survey among the informants shows that when people really had a health problem, more than $75 \%$ received both 'western' treatment and TCM. Only about 5\% claimed that they had never broken the rules of food restrictions as most of them (65\%) failed to recall the long list of what exactly they should avoid taking together, and the majority of them $(80 \%)$ think the rules of food restrictions work as guidelines for a healthy lifestyle rather than rules to be adhered to rigorously. Generally speaking, people regard TCM as associated with long-term yangsheng practice, whilst western medicine is for hospitals, operations, and short-term treatment - these two can therefore co-exist and work together harmoniously.

It seems that it is not the media platform per se that is critical in determining what it is that people choose to believe (Wang 2016; Miller et al. 2016): CCTV, 
the mainstream mass media platform, is no more convincing to the elderly than the short video. The ethnography also seems to show that even though there are contesting voices about the veracity of traditional food restrictions on short video platforms, audiences are not necessarily more highly exposed to different or challenging ideas than they were in the pre-digital age (Miller et al. 2016). Since the short videos are shared with regular contacts who, in many cases, share similar ideas, social media can easily perpetuate ingrained attitudes.

\section{Conclusion}

Being extremely short, accessible, and social, the video clips this chapter introduces are an unprecedented form of communication in this digital age. The short video as a genre cannot be said to enhance the status of film as a high art form. Quite the contrary, the short videos played on smartphones held in people's palms represent the most mundane form of film one can possibly imagine. However, exactly because of these mundane characteristics, it requires the lens of historical and ethnographic analysis (Banks and Morphy 1997) to make sense of how and why the short video has become an integral part of the daily life of the retired population in Shanghai.

How people gain yangsheng knowledge, as well as maintain social relationships by watching and sharing short videos, leads us to reflect on the relationships between short videos, health, and personal relationships in the age of smartphones. It is impossible to make any sense of short videos without taking into account the context in which they get circulated and consumed online and offline (Okabe 2006; Pink 2001; Miller et al. 2016).

Traditional TCM yangsheng practice has been transformed by the digital age. As a platform, the short video, shared on social media, is neither traditional nor modern, neither a product of the east nor the west - it simply provides a new and safe place where the debate about traditional knowledge can continue, and where local authority finds ways both to challenge and to integrate into top-down public health directives. It is evident that the short video facilitates the dissemination of yangsheng traditions among the retired population and, in doing so, makes a major contribution to the ways in which the elderly can express care for each other (Dijck 2008). As part of an amplified regime of yangsheng in China, the new visual cultures of selfcare encourage the users to actively shape what they understand as China's ancient heritage to their own immediate needs, taking ownership of critical elements of their well-being - even as, within what otherwise might be enclaves of the isolated and elderly, they participate in the most cutting-edge and youthful technology.

Recent ethnographic research (Miller and Sinanne 2017) argues that the visual material on social media has introduced a 'new visibility' where the comparatively cost-free and effortless digital technology of smartphone and social media has enabled images to be produced, consumed, posted, and shared with unprecedented speed and coverage. Thanks to the availability of smartphones, faster mobile internet and a boom in short video apps, the exchange of short video clips has gained great popularity among the retired population. 
Along with this development in digital technology, there is an ever-growing and ever-deepening visual language among the elderly in mainland China (Wang 2016). Given the challenges that China faces with its ageing population and the breakdown of the family as the unit of care, understanding what sorts of clips are more likely to be watched and understood and circulated, and why, becomes critical. How the combination of the topic, the view, and the properties of the clip itself interact requires greater investment from the field of health-related communication to understand the potential of short videos to transform healthcare in China.

\section{Notes}

1 According to ERC research ethics the names of the participants as well as the residential compound are anonymised.

2 WeChat is the dominant smartphone-based social media platform in mainland China.

3 Having said so, one of the main concerns about the short video among the retirees is that it can take up a lot of space on their smartphones.

4 Figures for monthly active users (MAU) measure the success rate of online social games, social networking services and, increasingly, mobile apps. Typically, metrics are measured by counting the number of unique users during a specific measurement period, such as within the previous 30 days.

5 Huang Zheping (2018) The world's most popular iPhone app isn't Facebook or WhatsApp, 8 May 2018, https://qz.com/1272285/bytedances-music-video-app-douyintik-tok-is-the-most-downloaded-iphone-app-in-2018s-first-quarter/, accessed 20 March 2019.

6 Beiji qianjin yaofang, j.26, p. 465.

7 By saying 'we didn't have the chance' Ms Yu indicates the fact that her generation went through the Cultural Revolution in China (1967-1977), during which period schools nationwide ceased normal teaching and a whole generation of the young people at that time lost the chance of receiving proper education.

8 Beiji qianjin yaofang, j. 26, p. 465.

\section{Bibliography}

\section{Pre-modern sources}

Beiji qianjin yaofang 備急千金要方 (Recipes for Emergency-Preparedness Worth a Thousand GoldCoins) 652, Sun Simiao 孫思貌 (1955), Beijing: Renmin weisheng chubanshe.

\section{Modern sources}

Banks, M. and Morphy, H. (eds.) (1997) Rethinking Visual Anthropology, New Haven, CT: Yale University Press.

Chambers, D. (2013) Social Media and Personal Relationships: Online Intimacies and Networked Friendship, Basingstoke: Palgrave Macmillan.

Dear, D. (2012) 'Chinese Yangsheng: Self-Help and Self-Image', Asian Medicine, 7 (1): $1-33$.

Despeux, C. (2007) Food Prohibitions in China, trans. P. Barrett, The Lantern: A Journal of Traditional Chinese Medicine, 4 (1): 22-32. 
Dijck, J.V. (2008) Digital Photography: Communication, Identity, Memory, Visual Communication, 7: 57-76.

Huang Zheping (2018) The World's Most Popular iPhone App Isn't Facebook or Whats App, Quartz, 8 May 2018, https://qz.com/1272285/bytedances-music-video-appdouyin-tik-tok-is-the-most-downloaded-iphone-app-in-2018s-first-quarter/, accessed 20 March 2019.

Lo, V. (2005) Pleasure, Prohibition and Pain: Food and Medicine in China, in Roel Sterckx (ed.) Of Tripod and Palate, London: Palgrave Macmillan, pp. 163-86.

Lo, V. and Re'em, E. (2018) Recipes for Love in the Ancient World, in G.E.R. Lloyd (ed.) Comparing Ancient Greece and China: Interdisciplinary and Cross-Cultural Perspectives, Cambridge: Cambridge University Press, pp. 326-52.

Lomborg, S. (2014) Social Media, Social Genres: Making Sense of the Ordinary, New York: Routledge.

Miller, D. and Slater, D. (2000) The Internet: An Ethnographic Approach, Oxford: Berg.

Miller, D. and Sinanne, J. (2017) Visualising Facebook, London: UCL Press.

Miller, D. et al. (2016) How the World Changed Social Media, London: UCL Press.

Mohammid, S. (2017) Digital Media, Learning and Social Confidence: An Ethnography of a Small Island, Knowledge Society, PhD thesis, RMIT University.

Okabe, D. (2006) Everyday Contexts of Camera Phone Use: Steps Toward Techno-social Ethnographic Frameworks, in J. Höflich and M. Hartmann (eds.) Mobile Communications in Everyday Life: An Ethnographic View, Berlin: Frank and Timme, pp. 79-102.

Pink, S. (2001) Doing Ethnography: Images, Media and Representation in Research, London: Sage.

Taylor, K. (2005) Chinese Medicine in Early Communist China, 1945-63: A Medicine of Revolution, London and New York: RoutledgeCurzon.

Unschuld, P. (1986) Medicine in China: A History of Pharmaceutics, Berkeley: University of California.

Wang, X. (2016) Social Media in Industrial China, London: UCL Press. 